\title{
A high-protein diet is anti-steatotic and has no pro-inflammatory side effects in dyslipidaemic APOE2 knock-in mice
}

\author{
Sonia C. Garcia Caraballo ${ }^{1,2} \dagger$, Tine M. Comhair ${ }^{1,2,3} \dagger$, Cornelis H. C. Dejong ${ }^{2,4}$, Wouter H. Lamers ${ }^{1,2,3,5}$ \\ and S. Eleonore Köhler ${ }^{1,2 *}$ \\ ${ }^{1}$ Department of Anatomy and Embryology, Maastricht University, The Netherlands \\ ${ }^{2}$ NUTRIM School of Nutrition, Toxicology and Metabolism, Maastricht University, The Netherlands \\ ${ }^{3}$ Nutrigenomics Consortium, Top Institute of Food and Nutrition, Wageningen, The Netherlands \\ ${ }^{4}$ Department of General Surgery, Maastricht University, Maastricht, The Netherlands \\ ${ }^{5}$ Tytgat Institute for Liver and Intestinal Research, Academic Medical Center, University of Amsterdam, Amsterdam, \\ The Netherlands
}

(Submitted 11 November 2013 - Final revision received 8 June 2014 - Accepted 13 June 2014 - First published online 27 August 2014)

\begin{abstract}
High-protein (HP) diets are effective anti-steatotic treatment options for patients with non-alcoholic fatty liver disease, but whether these diets also decrease steatosis in hyperlipidaemic conditions is not known. The aim of the present study was to determine the effects of a HP diet on hepatic steatosis and inflammation in hyperlipidaemic mice. Hyperlipidaemic male and female APOE2 knock-in (APOE2ki) mice were fed a semi-synthetic low-protein (LP) or HP diet in combination with a low-fat diet or a high-fat diet for 3 weeks. The HP diets reduced hepatic fat and cholesterol concentrations to $40-55 \%$ of those induced by the corresponding LP diets and attenuated hepatic inflammation mildly. The VLDL-associated plasma cholesterol concentrations decreased to 60-80\%, but those of TAG increased 3-4-fold. APOE2-mediated restriction of fat import into the liver did not modify the effects of a HP diet previously observed in wild-type mice. Female APOE2ki mice exhibited a higher expression of lipogenic, cholesterol-synthesising, inflammatory and cell-stress genes than wild-type female or male APOE2ki mice, but a similar response to HP diets. Low Apob expression and unchanged plasma APOB100 concentrations suggest that HP diets increase the plasma concentrations of TAG by slowing their clearance. The decrease in plasma leptin and hepatic fat and glycogen concentrations and the increase in fatty acid-oxidising gene and phosphoenolpyruvate carboxykinase 1 protein expression suggest a HP diet-mediated increase in mitochondrial metabolism. In conclusion, a HP diet reduces hepatic lipid content in dyslipidaemic mice and lowers the activation status of inflammatory cells in the liver.
\end{abstract}

\section{Key words: Hyperlipidaemia: Non-alcoholic steatohepatitis: High-protein diets: Non-alcoholic fatty liver disease:} APOE2 knock-in

Non-alcoholic fatty liver disease (NAFLD) encompasses a spectrum of liver pathologies that range from steatosis to non-alcoholic steatohepatitis ${ }^{(1)}$. Individuals with a fatty liver have an up to 2-fold increased rate of lipolysis, anaplerotic flux via pyruvate carboxylase, oxidative flux through the TCA cycle, ketogenesis and gluconeogenesis ${ }^{(2,3)}$, suggesting that a high hepatic or muscle cell lipid content brings about an increased rather than a deficient fatty acid oxidation ('supply-side' metabolic control). Incompletely oxidised lipotoxic by-products of fatty acid metabolism, such as NEFA, (lyso)phosphatidic acid, lysophospatidylcholines, ceramides and diacylglycerols, may accumulate in steatotic hepatocytes $^{(4,5)}$. The subsequent loss of insulin sensitivity then allows an increased rate of gluconeogenesis and mitochondrial TCA cycle metabolism ${ }^{(6)}$. Fatty hepatocytes have also been reported to secrete mediators that activate the pro-fibrotic stellate cells ${ }^{(7)}$. Furthermore, liver steatosis is an independent risk factor for patients undergoing major

Abbreviations: Acox, acetyl-CoA oxidase; APOE2ki, APOE2 knock-in (Apoe $\left.{ }^{t m\left(A P O E^{*} 2\right) M a e}\right)$; E\%, percentage of energy; FGF21, fibroblast growth factor 21; FPLC, fast protein liquid chromatography; HF, high fat; HP, high protein; ITGAM, integrin $\alpha M$ (also known as CD11b); LF, low fat; LP, low protein; LY6G, lymphocyte antigen 6G; MPO, myeloperoxidase; NAFLD, non-alcoholic fatty liver disease; PL, phospholipids; Srebf, sterol regulatory elementbinding transcription factor; TC, total cholesterol.

*Corresponding author: Dr S. E. Köhler, fax +31 43 3884134, email leo.koehler@maastrichtuniversity.nl

† These authors contributed equally to the present study. 
liver surgery ${ }^{(8)}$. Steatosis-reducing therapies are, therefore, a justifiable intervention for patients with NAFLD.

Rodents readily develop a diet-induced fatty liver, but steatosis only progresses to steatohepatitis in mice that are also dyslipidaemic, such as the $L d l r^{-/-}$( $L D L$ receptor $\left.{ }^{-/}\right)$, Apoe ${ }^{-1-}$ and Apoe $e^{\operatorname{tm} 1\left(A P O E^{*} 2\right) M a e}$ (APOE2 knock-in; APOE2ki) mouse strains ${ }^{(9-11)}$. These mice are hyperlipidaemic as they do not clear (V)LDL particles efficiently ${ }^{(12)}$. If fed a highfat (HF), high-cholesterol diet, the Kupffer cells in the liver of these mice become 'foamy', similar to macrophages in atherosclerotic plaques ${ }^{(10)}$. The resulting activation attracts inflammatory lymphocytes to the liver ${ }^{(13)}$. These findings emphasise the importance of Kupffer cells for the development of steatohepatitis.

We and others have recently shown that high-protein (HP) diets efficiently reduce diet-induced steatosis in the liver of wild-type rodents ${ }^{(14,15)}$. As a HF diet does not induce dyslipidaemia and hepatic inflammation in wild-type mice, it is important to establish whether such a diet is also effective in a hyperlipidaemic mouse model that is prone to develop hepatic inflammation, because this condition often occurs in human patients. The aim of the present study was, therefore, to establish whether the same HP diets that reduced steatosis in wild-type mice also exerted this effect in hyperlipidaemic APOE2ki mice ${ }^{(10)}$ and whether these diets attenuated the severity of hepatic inflammation in these inflammation-prone mice ${ }^{(10,11)}$ as well. The main finding of the present study on the early effects of a HP diet is that it reduced the hepatic lipid content in APOE2ki mice to a similar extent as in wild-type mice. Although a HP diet did not eliminate the activated macrophages and neutrophils from the liver, it reduced the expression of inflammatory markers quantitatively.

\section{Materials and methods}

Detailed protocols and details of materials and antibodies used are given in online supplementary Tables S1 and S2, respectively.

\section{Animals}

A total of seventy-six male and female hyperlipidaemic

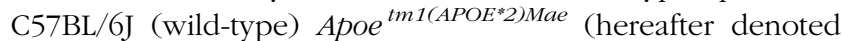
APOE2ki) mice were kindly provided by P. van Gorp (Department of Molecular Genetics, University of Maastricht). In APOE2ki mice, the mouse Apoe gene is replaced by the $\varepsilon 2$ isoform of the human $A P O E$ gene ${ }^{(16)}$. In total, eight to ten 8-9-week-old mice per intervention group (four dietary groups per sex) were kept in a temperature-controlled facility with two mice per cage, under a fixed $12 \mathrm{~h}$ light $-12 \mathrm{~h}$ dark cycle and with free access to food and water. Food intake (per cage) and body weight were measured twice weekly. The inflammatory response to a $\mathrm{HF}$ diet in the liver of APOE2ki mice is maximal between 1 and 3 weeks ${ }^{(17)}$. Therefore, mice were killed after 3 weeks on the specified diet. Mice were given access to food until killing. To avoid chronobiological effects, mice were anaesthetised in the morning
(10.00-12.30 hours) by intraperitoneal injection of a solution containing $52.5 \mathrm{mg} / \mathrm{kg}$ midazolam, $105 \mathrm{mg} / \mathrm{kg}$ fluanisone and $3.3 \mathrm{mg} / \mathrm{kg}$ fentanyl citrate and exsanguinated by harvesting blood from the inferior caval vein. Livers and epididymal fat pads were sampled, weighed and snap-frozen for further analysis. The study was approved by the Committee for Animal Care and Use of Maastricht University.

\section{Diets and experimental groups}

A total of four semi-synthetic diets (online supplementary Table S3) were purchased from Research Diets, Inc. The diets were formulated to determine the effect of HP content in a low-fat $(\mathrm{LF}=$ control) or a HF (steatotic) diet. The LF, low-protein (LP) diet contained $8 \%$ of energy (E\%) fat and $11 \mathrm{E} \%$ protein; the $\mathrm{LF} / \mathrm{HP}$ diet $8 \mathrm{E} \%$ fat and $35 \mathrm{E} \%$ protein; the $\mathrm{HF} / \mathrm{LP}$ diet $42 \mathrm{E} \%$ fat and $11 \mathrm{E} \%$ protein; and the $\mathrm{HF} / \mathrm{HP}$ diet $42 \mathrm{E} \%$ fat and $35 \mathrm{E} \%$ protein. Olive oil and casein were used as sources of fat and protein, respectively. The daily protein requirement of adult mice is met by $11 \mathrm{E} \%$ protein $^{(18)}$. Faecal samples were tested for complete absorption of dietary $\mathrm{fat}^{(15)}$. The concentrations of TAG did not exceed $140 \mu \mathrm{g}$ TAG/100 $\mathrm{g}$ faecal dry mass and did not depend on the protein content of the diets (data not shown).

\section{Quantification of mRNA}

Quantification of mRNA was performed by real-time PCR using 18S rRNA as a reference. For graphic presentation, $18 S$-corrected values were divided by the mean of the male LF/LP mouse group (100\%). Primer sequences and measured amplicon concentrations for each gene are given in online supplementary Tables S4 and S5, respectively.

\section{Immunohistochemistry}

Frozen liver sections $(7 \mu \mathrm{m})$ were stained to detect for the presence of cluster of differentiation 68 (CD68)-positive cells (residential phagocytic macrophages) and integrin $\alpha \mathrm{M}$ (ITGAM)-positive cells (CD11b/Mac-1; activated/infiltrated macrophages). The sections were scored independently by three people (S. C. G. C., T. M. C. and S. E. K.), who were blinded to the underlying experimental condition, and the scores are given as median and quartile values per three fields $\left(3.7 \mathrm{~mm}^{2}\right.$ each) per group, as described previously ${ }^{(11)}$. The liver sections were scored as follows: score $0-n<10$ positive cells, no ITGAM-positive cell foci; score $1-10<n<100$ positive cells, no foci; score $2-n>100$ positive cells or presence of foci; score $3-n>100$ positive cells and presence of foci.

To evaluate whether ITGAM-positive cell infiltration reflects neutrophil infiltration, paraffin-embedded liver sections $(5 \mu \mathrm{m})$ were stained to detect for the presence of myeloperoxidase (MPO)- and lymphocyte antigen 6G (LY6G)-positive cells and scored as described for ITGAM-positive cell foci. The liver sections were scored as follows: score $0-$ no foci or $<100$ neutrophils and score $1-$ presence of $>2$ foci or $>100$ neutrophils per three fields. 


\section{Plasma analysis}

Heparinised blood was obtained from the inferior caval vein and stored at $-80^{\circ} \mathrm{C}$. The plasma concentrations of lipids, hormones, ketone bodies and glucose were determined using commercially available kits or established methods. The concentration of venous whole-blood glucose was also measured in $4 \mathrm{~h}$ fasted mice $2 \mathrm{~d}$ before killing. Fast protein liquid chromatography (FPLC) analysis was performed on pooled plasma ( $n$ 10-12) of each group. The plasma concentration of cholesterol was determined in each fraction. Fractions obtained from male APOE2ki mice were pooled as described for the measurement of TAG concentration.

\section{SDS-PAGE of fast protein liquid chromatography fractions}

SDS-PAGE of FPLC fractions was performed as described by Horton et $a l^{(19)}$. Pooled plasma $(40 \mu \mathrm{l})$ of male APOE2ki mice was delipidated with $400 \mu \mathrm{l}$ of diethyl ether-ethanol (1:1) for $18 \mathrm{~h}$ at $-20^{\circ} \mathrm{C}$ and centrifuged for $30 \mathrm{~min}$ at $10000 \mathrm{rpm}$. The pellet was washed once with $200 \mu \mathrm{l}$ of $100 \%$ ethanol. Proteins were redissolved in $20 \mu \mathrm{l}$ of loading buffer, of which $10 \mu \mathrm{l}$ were loaded on a $4-15 \%$ polyacrylamide gradient gel. Proteins were stained with ruthenium (II) tris(bathophenanthroline disulfonate) tetrasodium salt (RubiLAB) and visualised under UV light.

\section{Liver analysis}

The concentrations of lipids (TAG, NEFA, phospholipids (PL) and total cholesterol (TC)) and proteins in liver homogenates were determined using commercially available kits. The hepatic concentration of glycogen was measured as described by Roehrig \& Allred $^{(20)}$.

\section{Western blotting}

Hepatic proteins were extracted in a lysis buffer containing phosphatase and protease inhibitors. The concentration of proteins was determined with a bicinchoninic acid assay. Blots were stained with Ponceau S (Brunschwig Chemie) to check for equal loading. The membranes were probed with antibodies listed in online supplementary Table S2.

\section{Statistical analysis}

A three-way ANOVA was used to test for differences between the main effects and possible interactions of protein and fat contents of the diets and the sex of the mice. The significance levels of this ANOVA for each of the pertinent figures and tables are summarised in online supplementary Tables S6(A)-(G). $P$ values $<0.05$ were considered significant, and $P$ values $<0 \cdot 1$ were considered to indicate a trend.

ITGAM scores were analysed using the non-parametric Whitney $U$ test, with $\mathrm{LF} / \mathrm{LP} \quad v$. LF/HP, HF/LP $v$. HF/HP, and male $v$. female as pairwise comparisons. The frequency of scores 0 and 1 for MPO- and LY6G-positive cells in liver sections with a low (scores 0 and 1) or a high ${ }^{(3)}$ score $^{2}$ for ITGAM-positive cells was analysed using Fisher's exact probability test.

\section{Results}

High-protein and high-fat diets have opposing effects on energy intake and fat-pad weight

The HP diets decreased food intake, whereas the HF diets increased it $(P=0.002$ and $P=0.001$, respectively), with a strong negative interaction $(P=0.002)$ that cancelled out the effects of the HF/HP diet (Table 1, online supplementary Table S6(A)). In agreement with this, male and female APOE2ki mice fed the HF/LP diet had approximately $30 \%$ higher energy intake than those fed the other diets. Body weight remained stable in both sexes throughout the 3-week intervention period. Liver weight decreased in mice fed the HF diets $(P=0.050)$, an effect that was more pronounced in male mice than in female mice $(P<0 \cdot 001)$ The HP diets decreased fat-pad weight, whereas the HF diets increased it $(P=0.020$ and $P<0.001$, respectively). The effect was stronger in male mice than in female mice $(P<0 \cdot 001)$.

\section{High-protein diets decrease hepatic lipid content}

The HP diets decreased the hepatic concentrations of TAG in both male and female APOE2ki mice to $40-55 \%$ of those in mice fed the corresponding LP diets $(P<0 \cdot 001$; Fig. 1(a); online supplementary Table S6(B)). We determined both lipid and protein contents in a small sample of the liver of each mouse and expressed the lipid content as mmol/g protein. We have previously shown that the quantification of Oil Red O staining (amount of lipid/volume of liver) is significantly correlated with the biochemical quantification of hepatic lipids ${ }^{(11)}$. Fig. 1(a) clearly shows that there was a dramatic reduction in hepatic lipid content, as determined by Oil Red O staining, in mice fed the HP diets than in those fed the LP diets. This shows that the observed $\mathrm{mmol}$ lipid/g protein decrease is due to a decrease in hepatic lipid content. That this decrease was not due to an increase in hepatic protein content was confirmed in three samples of mice fed the LF/LP or the LF/HP diet, in which the protein content per $\mathrm{g}$ hepatic tissue did not vary with the protein content of the diet (mean 163 (SD 15) and 158 (SD 15) mg protein/g liver in LF/LP and LF/HP mice, respectively; $n$ 3). The hepatic concentrations of NEFA (Fig. 1(b)), TC (Fig. 1(c)) and PL (Fig. 1(d)) were similarly reduced in mice fed the HP diets (all $P<0.001$ ). The effect of a high dietary protein content on the hepatic concentrations of PL was significant in female mice than in male mice ( $\mathrm{HP} \times$ sex: $P=0 \cdot 03)$. A high dietary fat content increased the hepatic concentrations of TAG and TC $(P=0 \cdot 013$ and $P=0 \cdot 017$, respectively). Female APOE2ki mice consistently had $1 \cdot 4-1 \cdot 8$-fold higher hepatic lipid content than male mice (all $P<0 \cdot 001$ ). 
Table 1. Biometric data of APOE2 knock-in mice fed diets differing in protein and fat contents for 3 weeks*

(Mean values with their standard errors; $n$ 10-12 mice per group)

\begin{tabular}{|c|c|c|c|c|c|c|c|c|}
\hline & \multicolumn{2}{|c|}{ LF/LP } & \multicolumn{2}{|c|}{ LF/HP } & \multicolumn{2}{|c|}{ HF/LP } & \multicolumn{2}{|c|}{$\mathrm{HF} / \mathrm{HP}$} \\
\hline & Mean & SEM & Mean & SEM & Mean & SEM & Mean & SEM \\
\hline \multicolumn{9}{|c|}{ Body weight† (g) } \\
\hline Male & $24 \cdot 2$ & 0.60 & $25 \cdot 2$ & 0.40 & $24 \cdot 1$ & 0.50 & $25 \cdot 0$ & 0.60 \\
\hline Female & $19 \cdot 8$ & 0.60 & $19 \cdot 8$ & 0.30 & 21.4 & 0.50 & $20 \cdot 5$ & 0.60 \\
\hline \multicolumn{9}{|c|}{ Energy intake $(\mathrm{kJ} / \mathrm{d})$} \\
\hline Male & $52 \cdot 7$ & 1.20 & $56 \cdot 9$ & $2 \cdot 50$ & $68 \cdot 6$ & 3.80 & $56 \cdot 5$ & $2 \cdot 10$ \\
\hline Female & $53 \cdot 1$ & 0.80 & $49 \cdot 4$ & 0.80 & $71 \cdot 1$ & $2 \cdot 50$ & 51.5 & 0.80 \\
\hline \multicolumn{9}{|c|}{$\Delta$ Body weight $¥$ (g) } \\
\hline Male & 0.78 & 0.11 & -0.21 & 0.70 & 1.06 & 0.16 & 0.85 & 0.29 \\
\hline Female & 1.03 & 0.91 & 0.95 & 0.32 & 0.60 & 0.33 & 0.86 & 0.42 \\
\hline \multicolumn{9}{|c|}{ Liver weight§ (g) } \\
\hline Male & 1.41 & 0.06 & 1.48 & 0.04 & $1 \cdot 26$ & 0.04 & 1.4 & 0.05 \\
\hline Female & 1.33 & 0.05 & 1.23 & 0.06 & 1.18 & 0.04 & $1 \cdot 21$ & 0.02 \\
\hline \multicolumn{9}{|c|}{ Fat-pad weight§॥ $(\mathrm{g})$} \\
\hline Male & 0.33 & 0.02 & 0.26 & 0.02 & 0.43 & 0.03 & 0.33 & 0.01 \\
\hline Female & 0.21 & 0.03 & 0.19 & 0.03 & 0.26 & 0.02 & 0.26 & 0.04 \\
\hline
\end{tabular}

LF, low fat; LP, low protein; HP, high protein; HF, high fat.

${ }^{*} P$ values of the three-way ANOVA (HP, HF and sex) and interactions $(\mathrm{HP} \times \mathrm{HF}, \mathrm{HP} \times \operatorname{sex}, \mathrm{HF} \times \operatorname{sex}$ and $\mathrm{HF} \times \mathrm{HP} \times \operatorname{sex})$ are given in online supplementary Table S6(A).

† Body weight at start of the experiment.

$\ddagger$ The absolute change in weight from the start to the end of the experiment.

$\S$ Liver and fat-pad weights measured at the time of killing.

\| Fat-pad weight denotes the epididymal fat-pad weight in male mice and the inguinal fat-pad weight in female mice.

High-protein diets increase plasma TAG concentrations, but decrease plasma cholesterol and phospholipid concentrations

The HP diets increased the plasma concentrations of TAG (approximately 2-fold), decreased those of TC and PL, and had no significant effect on those of NEFA $(P<0 \cdot 001$, $P<0.001, P=0.001$ and $P=0 \cdot 081$, respectively), whereas the HF diets increased the plasma concentrations of all the four compounds $(P<0.001, \quad P=0.030, \quad P=0.001$ and $P=0.003$, respectively; Fig. 2, online supplementary Table S6(C)). Female mice had lower plasma concentrations of TAG and higher plasma concentrations of TC than male mice $(P<0.001$ and $P=0 \cdot 013$, respectively). The elevating effects of a high dietary protein content on the plasma
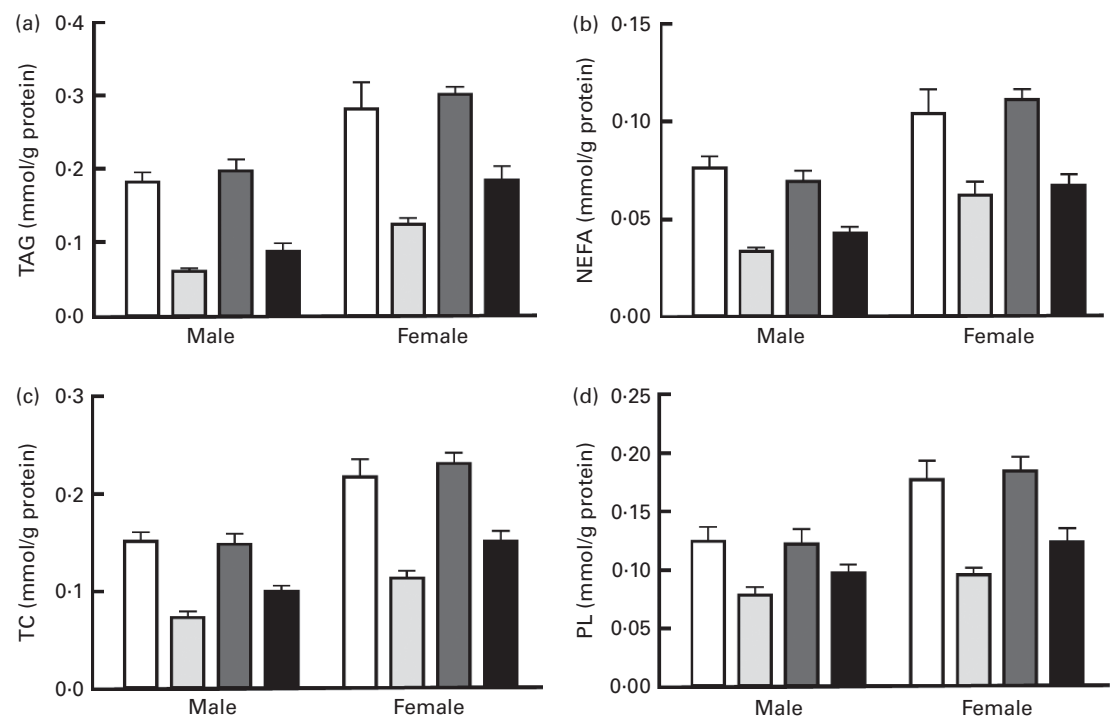

Fig. 1. Hepatic lipid concentrations in APOE2 knock-in mice fed diets differing in protein and fat contents for 3 weeks. (a) Hepatic TAG; (b) NEFA; (c) total cholesterol (TC); and (d) phospholipids (PL). Values are means, with their standard errors represented by vertical bars. The results of the three-way ANOVA (high protein $(\mathrm{HP})$, high fat $(\mathrm{HF})$ and sex) and their interactions of the three-way ANOVA (high protein $(\mathrm{HP})$, high fat (HF) and sex) and interactions $(\mathrm{HP} \times \mathrm{HF}$, $\mathrm{HP} \times$ sex, HF $\times$ sex and HF $\times \mathrm{HP} \times$ sex) are given in online supplementary Table S6(B). $\square$, Low fat (LF)/low protein (LP); $\square, \mathrm{LF} / \mathrm{HP} ; \square, \mathrm{HF} / \mathrm{LP} ; \mathbf{\square}, \mathrm{HF} / \mathrm{HP}$. 

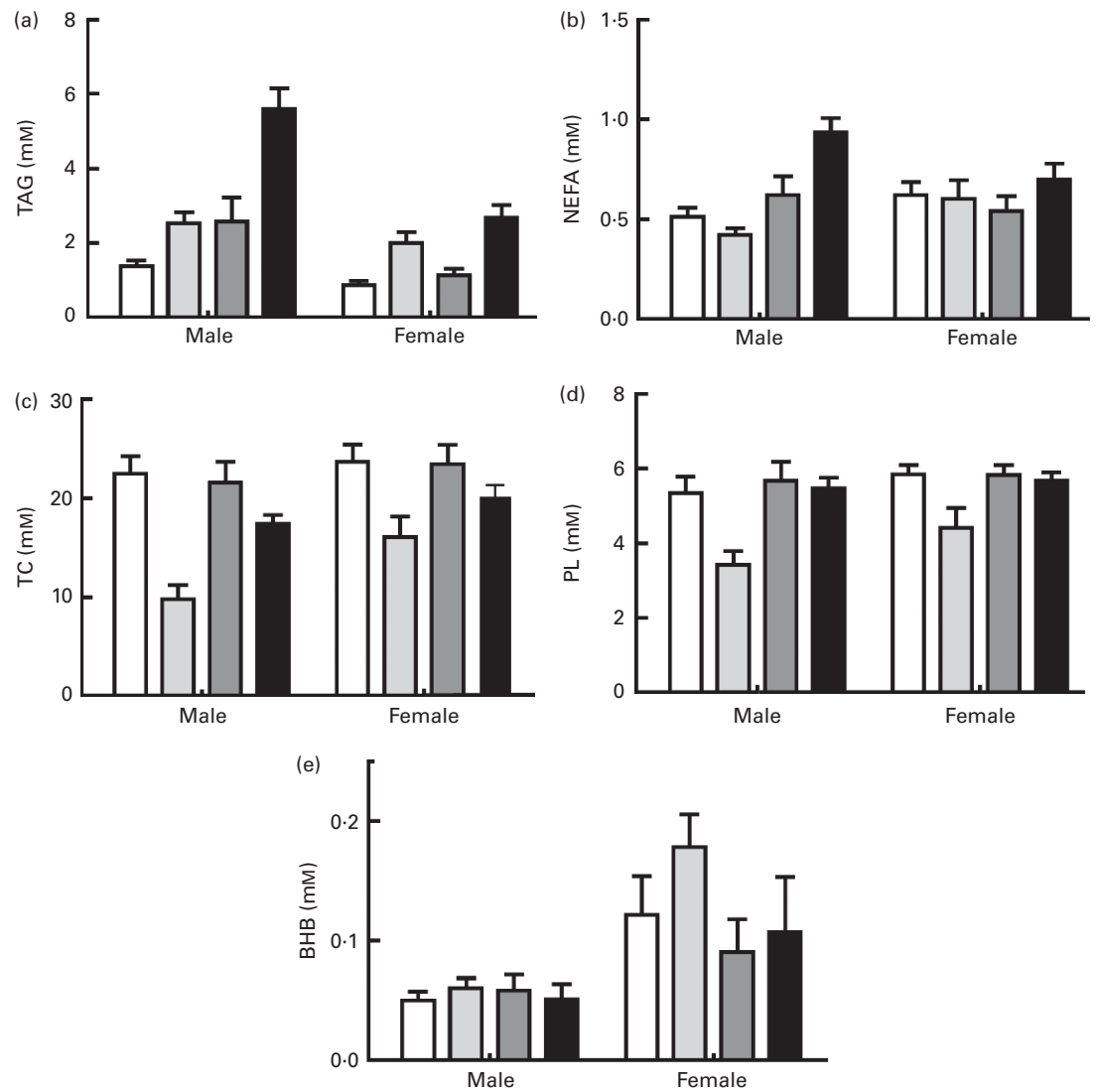

Fig. 2. Plasma lipid concentrations in APOE2 knock-in mice fed diets differing in protein and fat contents for 3 weeks. (a) TAG; (b) NEFA; (c) total cholesterol (TC); (d) phospholipids (PL); and (e) $\beta$-hydroxybutyrate (BHB). Values are means, with their standard errors represented by vertical bars. The calculated effects of the three-way ANOVA (high protein (HP), high fat (HF) and sex) and interactions $(\mathrm{HP} \times \mathrm{HF}, \mathrm{HP} \times$ sex, $\mathrm{HF} \times$ sex and $\mathrm{HF} \times \mathrm{HP} \times \operatorname{sex})$ are given in online supplementary Table S6(C). $\square$, Low fat (LF)/low protein (LP); $\square, \mathrm{LF} / \mathrm{HP} ; \square, \mathrm{HF} / \mathrm{LP} ; \mathbf{\square}, \mathrm{HF} / \mathrm{HP}$.

concentrations of TAG and NEFA were more pronounced in the presence of a high dietary fat content $(\mathrm{HP} \times \mathrm{HF}$ : $P=0.055$ and $P=0.006$, respectively), in particular, in male mice (HF $\times$ sex: $P=0.006$ and $P=0.004$, respectively). The HP diets were less effective at lowering plasma TC and PL concentrations, when mice were also fed a HF diet $(\mathrm{HP} \times \mathrm{HF} ; P=0.009$ and $P=0.006$, respectively). Compared with male mice, female APOE2ki mice had approximately 2-fold lower plasma concentrations of TAG $(P<0.001)$ and approximately 2 -fold higher plasma concentrations of the ketone body $\beta$-hydroxybutyrate (Fig. 2(e); $P<0 \cdot 001$ ). Furthermore, the plasma concentrations of TC were also slightly higher in female mice than in male mice $(P=0.013)$. There was no effect of the diets on the plasma concentrations of $\beta$-hydroxybutyrate.

Lipoproteins, especially VLDL, accumulate in the plasma of APOE2ki mice ${ }^{(16)}$. FPLC analysis of plasma showed that the VLDL and LDL fractions had the highest concentrations of TC and TAG. In agreement with the results of the unfractionated plasma analysis carried out in the present study, the plasma (V)LDL fraction of mice fed the HP diets $v$. those fed the LP diets had low cholesterol content, with the effect being more pronounced in combination with a LF diet than with a HF diet and also more pronounced in male mice than in female mice (Fig. 3(a) and (b)). In further agreement with the results of the unfractionated plasma analysis, the concentrations of TAG, measured in pooled FPLC fractions of plasma of male mice only, were 3-4-fold higher in the VLDL fraction of mice fed the HP diets than in those fed the LP diets (Fig. 3(c)). The plasma concentrations of APOB100, APOB48 and APOE were highest in mice fed the LF/LP diet (Fig. 3(d)) and correlated better with the dietary carbohydrate content than with the dietary protein or fat content (Fig. 3(e)). A similar correlation between plasma APOB100 and APOB48 concentrations and dietary carbohydrate content was demonstrated in hypertriacylglycerolaemic human subjects ${ }^{(21)}$.

\section{Effects of a high dietary protein content on markers of lipogenesis, lipid oxidation and cholesterol synthesis}

The markers of lipogenesis, fatty acid oxidation and cholesterol synthesis was analysed in the present study (Table 2, online supplementary Table S6(D)). A high dietary protein content decreased the expression of Pparg, acetyl-CoA carboxylase- $\alpha$ (Acaca) and fatty acid synthase (Fasn) $(P=0.004$, $P=0.003$ and $P=0.014$, respectively), but it did not affect that of other lipogenic genes. A high dietary fat content decreased the expression of all genes studied (all $P \leq 0 \cdot 014$ ), 


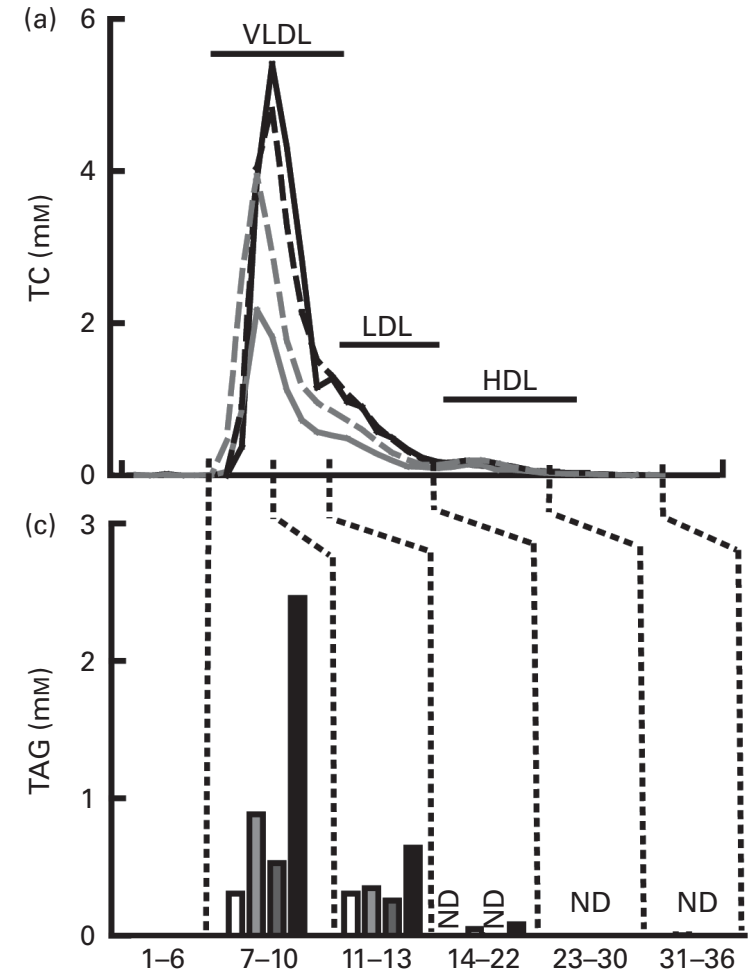

(d)

Pooled fractions: 1-6 $\quad 7-10 \quad 11-13 \quad 14-21 \quad 23-30 \quad 31-36$

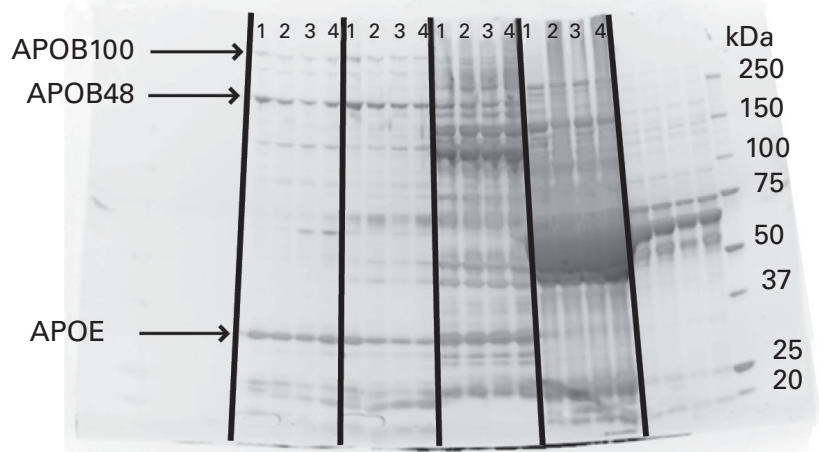

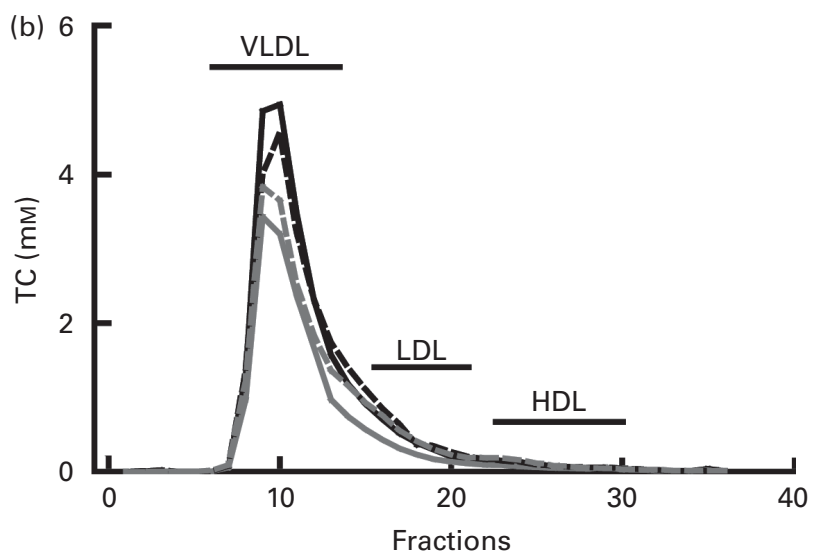

(e)

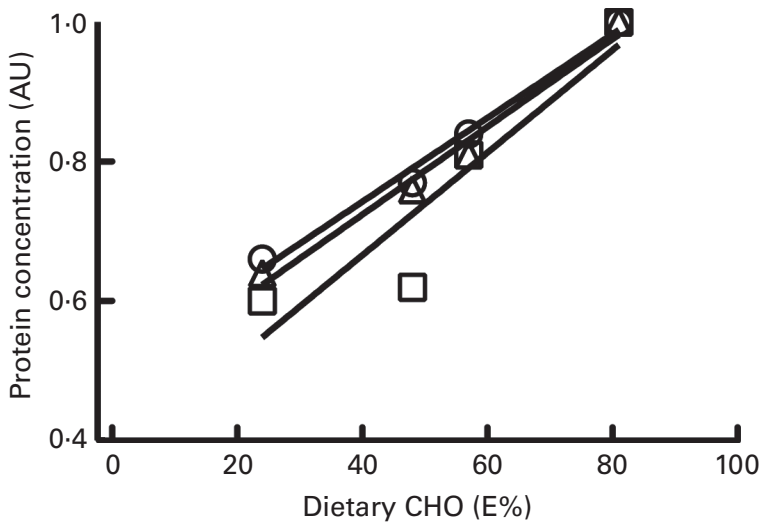

Fig. 3. Results of the fast protein liquid chromatography (FPLC) analysis of plasma of APOE2 knock-in (APOE2ki) mice fed diets differing in protein and fat contents for 3 weeks. Total cholesterol (TC) content of the FPLC fractions of pooled plasma of (a) male and (b) female mice fed a high-fat (HF) diet in combination with a low-protein (LP; --) or a high-protein (HP; --) diet or a low-fat (LF) diet in combination with a LP (-) or a HP (-) diet. (c) TAG content in the indicated pools of FPLC fractions of plasma of male APOE2ki mice. Note that the lowest TC and highest TAG concentrations were found in the plasma of mice

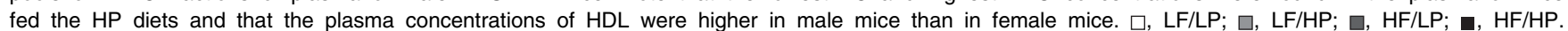
(d) SDS-PAGE gel with pooled FPLC fractions of male APOE2ki mice. The numbers 1-4 above the lanes indicate the respective dietary groups, with 1=LF/LP; $2=\mathrm{LF} / \mathrm{HP} ; 3=\mathrm{HF} / \mathrm{LP}$; and $4=\mathrm{HF} / \mathrm{HP}$. (e) Results of a densitometric analysis of the SDS-PAGE gel. The quantities of APOB100, APOB48 and APOE proteins in fractions 7-21 (determined by integrating the optical density values of the APOB100, APOB48 and APOE protein bands) were corrected for total protein content in these lanes and were plotted against the protein content of the respective diets. The $R^{2}$ values for the association of APOB100, APOB48 and APOE concentrations with the carbohydrate $(\mathrm{CHO})$ content of the diet were $0.99,0.86$ and 0.98 , respectively. $\square$, APOB100; $\triangle$, APOB48; O, APOE. ND, not determined; $\mathrm{AU}$, arbitrary unit.

except that of sterol regulatory element-binding transcription factor (Srebf)1 and MLX-interacting protein-like/carbohydrate-responsive element-binding protein (Mlxipl/Chrebp). Furthermore, all the studied lipogenic genes were more highly expressed in female mice than in male mice (all $P \leq 0.006$ ). Many interactions were found for Srebf 1 , where the effects of a high dietary protein content were less pronounced in female mice than in male mice $(\mathrm{HP} \times$ sex: $P=0.071 ; \mathrm{HF} \times$ sex: $P=0.019)$. The expression of $M l x i p l$ was not significantly affected by the diets or sex, but it had a significant residual variation $(\mathrm{HP} \times \mathrm{HF} \times \mathrm{sex})$. Such residual variation was also found for Srebf1 and Acaca.

A high dietary protein content had few effects on the expression of genes linked to fatty acid oxidation, but 
Table 2. Hepatic expression of marker genes for lipogenesis, fatty acid oxidation and cholesterol synthesis in APOE2 knock-in mice fed diets differing in protein and fat contents for 3 weeks*

(Mean values with their standard errors)

\begin{tabular}{|c|c|c|c|c|c|c|c|c|}
\hline & \multicolumn{2}{|c|}{ LF/LP } & \multicolumn{2}{|c|}{ LF/HP } & \multicolumn{2}{|c|}{$\mathrm{HF} / \mathrm{LP}$} & \multicolumn{2}{|c|}{$\mathrm{HF} / \mathrm{HP}$} \\
\hline & Mean & SEM & Mean & SEM & Mean & SEM & Mean & SEM \\
\hline \multicolumn{9}{|l|}{ Lipogenesis } \\
\hline \multicolumn{9}{|l|}{ Pparg } \\
\hline Male & 1.00 & 0.13 & 0.74 & 0.08 & 0.75 & $0 \cdot 15$ & 0.61 & 0.05 \\
\hline Female & 1.99 & 0.23 & 1.67 & 0.13 & 1.75 & 0.11 & $1 \cdot 27$ & 0.13 \\
\hline \multicolumn{9}{|l|}{ Srebf1 } \\
\hline Male & 1.00 & 0.08 & 0.50 & $0 \cdot 10$ & 0.49 & 0.06 & 0.63 & 0.04 \\
\hline Female & 1.36 & 0.14 & 1.65 & 0.22 & 1.76 & 0.13 & 1.95 & 0.17 \\
\hline \multicolumn{9}{|c|}{ MIxipl/Chrebp } \\
\hline Male & 1.00 & 0.09 & 0.63 & 0.05 & 0.62 & 0.06 & 0.59 & 0.05 \\
\hline Female & 0.71 & 0.05 & 1.05 & 0.13 & 1.09 & 0.14 & 0.85 & 0.12 \\
\hline \multicolumn{9}{|l|}{ Acaca } \\
\hline Male & 1.00 & 0.09 & 0.48 & 0.03 & 0.39 & 0.04 & 0.32 & 0.02 \\
\hline Female & 1.06 & 0.08 & 1.00 & $0 \cdot 12$ & 1.22 & 0.35 & 0.47 & 0.06 \\
\hline \multicolumn{9}{|l|}{ Fasn } \\
\hline Male & 1.00 & 0.22 & 0.59 & 0.04 & 0.38 & 0.11 & 0.35 & 0.06 \\
\hline Female & 1.62 & 0.24 & 1.56 & 0.30 & 1.20 & 0.19 & 0.69 & 0.10 \\
\hline \multicolumn{9}{|l|}{ Scd1 } \\
\hline Male & 1.00 & 0.14 & 0.82 & 0.09 & 0.37 & 0.04 & 0.41 & 0.09 \\
\hline Female & 0.95 & 0.08 & $1 \cdot 27$ & 0.12 & 0.84 & 0.11 & 0.61 & 0.09 \\
\hline \multicolumn{9}{|c|}{ Fatty acid oxidation } \\
\hline \multicolumn{9}{|l|}{ Ppara } \\
\hline Male & 1.00 & 0.08 & 1.04 & 0.04 & $1 \cdot 10$ & $0 \cdot 16$ & 1.06 & 0.20 \\
\hline Female & $2 \cdot 14$ & 0.31 & 1.85 & $0 \cdot 15$ & 2.09 & $0 \cdot 14$ & 2.05 & 0.18 \\
\hline \multicolumn{9}{|l|}{ Ppargc1 $\alpha$} \\
\hline Male & 1.00 & 0.17 & $1 \cdot 27$ & 0.09 & 0.82 & 0.14 & 1.07 & 0.07 \\
\hline Female & 1.24 & 0.09 & 1.74 & 0.19 & 1.40 & 0.18 & 1.60 & 0.13 \\
\hline \multicolumn{9}{|l|}{ Acox } \\
\hline Male & 1.00 & 0.13 & $1 \cdot 31$ & $0 \cdot 13$ & 0.75 & 0.07 & 0.93 & 0.08 \\
\hline Female & 0.85 & 0.06 & 1.19 & 0.11 & 1.03 & 0.07 & 0.97 & 0.08 \\
\hline \multicolumn{9}{|l|}{ Cpt1 } \\
\hline Male & 1.00 & 0.23 & 1.13 & 0.11 & 1.44 & 0.49 & 0.82 & 0.03 \\
\hline Female & 1.35 & 0.20 & 1.29 & 0.09 & 1.42 & $0 \cdot 10$ & 1.44 & 0.15 \\
\hline \multicolumn{9}{|l|}{ Hmgcs2 } \\
\hline Male & 1.00 & 0.10 & 0.84 & 0.08 & 0.72 & 0.07 & 0.81 & 0.07 \\
\hline Female & $1 \cdot 12$ & 0.08 & 1.2 & 0.13 & 1.47 & 0.12 & $1 \cdot 17$ & 0.11 \\
\hline Cd36 & & & & & & & & \\
\hline Male & 1.00 & 0.16 & 1.05 & 0.12 & 0.56 & 0.07 & 0.69 & 0.08 \\
\hline Female & $2 \cdot 74$ & 0.15 & 3.79 & 0.38 & 2.57 & 0.11 & $2 \cdot 53$ & 0.31 \\
\hline Cholesterol $\mathrm{n}$ & & & & & & & & \\
\hline Srebf2 & & & & & & & & \\
\hline Male & 1.00 & 0.09 & $1 \cdot 20$ & 0.05 & 0.79 & 0.08 & 0.97 & 0.11 \\
\hline Female & 1.53 & 0.08 & 1.64 & 0.11 & 1.55 & 0.23 & 1.43 & 0.10 \\
\hline Сур7а1 & & & & & & & & \\
\hline Male & 1.00 & 0.14 & $1 \cdot 10$ & 0.15 & 1.72 & 0.53 & 1.15 & 0.40 \\
\hline Female & 1.07 & 0.26 & 1.02 & 0.22 & $2 \cdot 12$ & 0.21 & 2.08 & 0.19 \\
\hline $\mathrm{Hmgcr}$ & & & & & & & & \\
\hline Male & 1.00 & 0.02 & $2 \cdot 56$ & 0.39 & 0.51 & 0.07 & 0.90 & 0.16 \\
\hline Female & 3.08 & 0.40 & 5.53 & 1.66 & 3.00 & 0.63 & $2 \cdot 18$ & 0.36 \\
\hline$A p o b$ & & & & & & & & \\
\hline Male & 1.00 & 0.08 & 0.86 & 0.06 & 0.82 & 0.05 & 1.01 & 0.12 \\
\hline Female & $1 \cdot 11$ & 0.09 & $1 \cdot 13$ & 0.20 & 1.28 & 0.07 & $1 \cdot 16$ & 0.09 \\
\hline Mttp & & & & & & & & \\
\hline Male & 1.00 & 0.11 & 0.81 & 0.05 & 0.59 & 0.04 & 0.65 & 0.07 \\
\hline Female & 0.76 & 0.03 & 0.85 & 0.12 & 0.86 & 0.09 & 0.71 & 0.07 \\
\hline
\end{tabular}

LF, low fat; LP, low protein; HP, high protein; HF, high fat; Srebf, sterol regulatory element-binding transcription factor; Mlxipl/Chrebp, MLX-interacting protein-like/carbohydrate-responsive element-binding protein; Acaca, acetyl-CoA carboxylase- $\alpha$; Fasn, fatty acid synthase; Scd1, stearoyl-CoA desaturase 1; Ppargc1a, Ppary co-activator 1 $\alpha$; Acox, acyl-CoA oxidase; Cpt1, carnitine palmitoyltransferase I; Hmgcs2, 3-hydroxy-3-methylglutaryl-CoA synthase 2; Cd36, cluster of differentiation 36/fatty acid translocase; Cyp7a1, cytochrome P450 7A1; Hmgcr, 3-hydroxy-3-methylglutaryl-CoA reductase; $M$ ttp, microsomal TAG-transfer protein.

*Values are expressed relative to the male LF/LP mouse group $(=1$; original data are given in online supplementary Table S5); results of the three-way ANOVA (HP, HF and sex) and their interactions $(\mathrm{HP} \times \mathrm{HF}, \mathrm{HP} \times \operatorname{sex}, \mathrm{HF} \times \operatorname{sex}$ and $\mathrm{HF} \times$ $\mathrm{HP} \times \operatorname{sex})$ are given in online supplementary Table S6(D). 
increased the expression of Ppar $\gamma$ co-activator $1 \alpha$ (Ppargc1a) and in LF condition (but not in HF; HP $\times \mathrm{HF}$, NS) that of the PPAR $\alpha$ target gene acetyl-CoA oxidase (Acox) $(P=0.037$ and $P=0.008$, respectively). In contrast, a high dietary fat content decreased the expression of $A c o x$ and cluster of differentiation 36/fatty acid translocase ( $C d 36)(P=0.023$ and $P=0.001$, respectively). The expression of Ppargc1a, 3-hydroxy-3-methylglutaryl-CoA synthase 2 (Hmgcs2), Ppara and especially $C d 36$ was higher in female mice than in male mice (all $P<0 \cdot 001$ ), whereas no difference was observed in the expression of Acox. The HF diets were more effective at lowering the expression of $A c o x$ in male mice than in female mice $(P=0.044)$. The expression of Ppara, carnitine palmitoyltransferase I (Cpt1) and Hmgcs2 was affected neither by the diets nor by sex.

The mRNA expression of markers of cholesterol metabolism in the liver was also analysed. The HP diets did not have a significant effect on any of the genes studied, but the HF diets increased the expression of the cholesterol- and bile acid-synthesising enzyme cytochrome $\mathrm{P}_{450} 7 \mathrm{~A} 1$ (Cyp7a1; $P=0.028)$ and decreased that of 3-hydroxy-3-methylglutarylCoA reductase $(\mathrm{Hmgcr})$ and microsomal TAG-transfer protein (Mttp) ( $P=0.009$ and $P=0.016$, respectively). The effects of a high dietary protein content on Cyp7a1 expression were stronger in female mice than in male mice $(P=0.028)$. The expression of $\mathrm{HmgCr}$ was further characterised by a negative interaction between a high dietary protein content and a high dietary fat content $(\mathrm{HP} \times \mathrm{HF}: P=0.038)$. Srebf $2, A p o B$ and $H m g c r$ were more highly expressed in female mice than in male mice (all $P<0 \cdot 003$ )

\section{A high dietary protein content increases hepatic phosphoenolpyruvate carboxykinase 1 expression, but has no effect on plasma glucose concentrations and reduces hepatic glycogen concentrations}

The HP diets had no effect on the plasma glucose concentrations of mice in the fed or the fasted condition, but the $\mathrm{HF}$ diets increased the blood glucose concentrations of male and female APOE2ki mice in the fed condition (Table 3, online supplementary Table S6(E); $P=0.004)$, although after $4 \mathrm{~h}$ of fasting only a moderate effect persisted in female mice (HF $\times$ sex: $P=0 \cdot 046$ ). The plasma concentrations of insulin were not affected by any of the diets (Table 3, online supplementary Table S6(E)). The HP diets tended to decrease the plasma concentrations of leptin (Table 3, online supplementary Table S6(E); $P=0.056$ ), in particular, in male mice (HP $\times$ sex: $P=0.031)$, and to increase those of glucagon $(P=0.059)$, in particular, in female mice (sex: $P=0.098)$.

Fig. 4(a) shows that both high dietary protein and fat contents significantly decreased hepatic glycogen content (online supplementary Table S6(F); $P=0.002$ and $P=0.001$, respectively). The distribution of stored glycogen shifted from a portocentral gradient (with the highest glycogen concentration in the periportal area) in LF diet-fed mice to a mostly pericentral accumulation in HF/LP diet-fed mice. The zonation of glycogen storage was greatly diminished or absent in HF/HP diet-fed mice (online supplementary Fig. S1). Male mice had significantly higher hepatic concentrations of glycogen than female mice $(P=0 \cdot 024)$. The HP diets significantly increased hepatic phosphoenolpyruvate carboxykinase 1 (Pck1) expression $(P<0 \cdot 001$; Fig. 4(b); online supplementary Table S6(F))

Table 3. Plasma glucose and hormone concentrations in APOE2 knock-in mice fed diets differing in protein and fat contents for 3 weeks*

(Mean values with their standard errors; $n$ 10-12)

\begin{tabular}{|c|c|c|c|c|c|c|c|c|}
\hline & \multicolumn{2}{|c|}{ LF/LP } & \multicolumn{2}{|c|}{ LF/HP } & \multicolumn{2}{|c|}{$\mathrm{HF} / \mathrm{LP}$} & \multicolumn{2}{|c|}{$\mathrm{HF} / \mathrm{HP}$} \\
\hline & Mean & SEM & Mean & SEM & Mean & SEM & Mean & SEM \\
\hline \multicolumn{9}{|c|}{ Fasting glucose $(\mathrm{mmol} / \mathrm{l})$} \\
\hline Male & $7 \cdot 8$ & 0.3 & $8 \cdot 2$ & 0.3 & 7.9 & 0.7 & $8 \cdot 1$ & 0.5 \\
\hline Female & $6 \cdot 3$ & 0.4 & $6 \cdot 8$ & 0.9 & $8 \cdot 7$ & 0.4 & 7.5 & 0.5 \\
\hline \multicolumn{9}{|c|}{ Fed glucose $(\mathrm{mmol} / \mathrm{l})$} \\
\hline Male & $7 \cdot 8$ & 0.5 & 8.4 & 0.5 & $9 \cdot 0$ & 0.7 & 9.4 & 0.8 \\
\hline Female & 7.4 & 0.5 & $7 \cdot 1$ & 0.4 & $9 \cdot 2$ & 1.0 & $9 \cdot 1$ & 0.6 \\
\hline \multicolumn{9}{|c|}{ Insulin (pmol/l) } \\
\hline Male & 102 & 25 & 209 & 34 & 153 & 27 & 157 & 25 \\
\hline Female & 182 & 55 & 105 & 10 & 102 & 10 & 101 & 14 \\
\hline \multicolumn{9}{|c|}{ Leptin (pmol/l) } \\
\hline Male & 398 & 99 & 212 & 47 & 318 & 38 & 259 & 43 \\
\hline Female & 266 & 83 & 237 & 53 & 296 & 17 & 281 & 41 \\
\hline \multicolumn{9}{|c|}{ Glucagon (pmol/l) } \\
\hline Male & 12 & 2 & 13 & 2 & 14 & 3 & 17 & 5 \\
\hline Female & 15 & 2 & 24 & 3 & 14 & 3 & 18 & 2 \\
\hline \multicolumn{9}{|c|}{ FGF21† (ng/ml) } \\
\hline Male & 1.3 & 0.3 & 0.4 & 0.1 & 2.5 & 1.3 & 0.3 & 0.2 \\
\hline Female & 1.3 & 0.3 & 0.8 & 0.2 & 0.9 & 0.1 & 0.5 & 0.1 \\
\hline
\end{tabular}

LF, low fat; LP, low protein; HP, high protein; HF, high fat; FGF21, fibroblast growth factor 21.

${ }^{*} P$ values of the three-way ANOVA (HP, HF and sex) and interactions (HP $\times$ HF, HP $\times$ sex, HF $\times$ sex and HF $\left.\times \mathrm{HP} \times \operatorname{sex}\right)$ are given in online supplementary Table S6(E).

†For the FGF21 assay, pooled plasma from three groups of two mice each was used. 
(a)

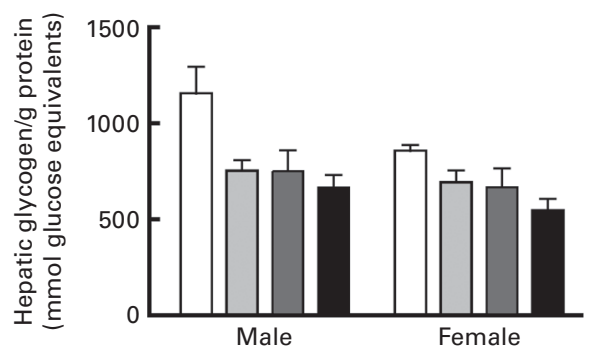

(b)

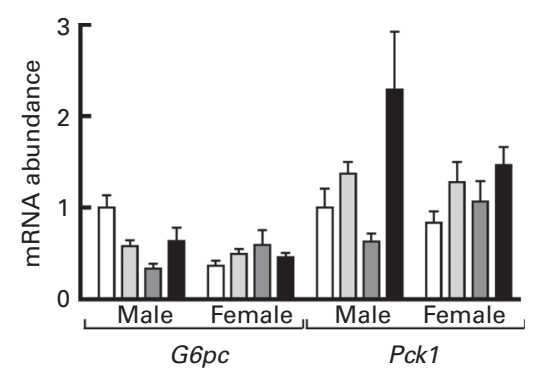

(c)

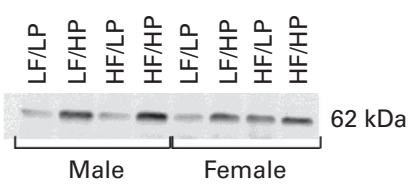

Fig. 4. Hepatic glycogen content and expression of gluconeogenic markers in APOE2 knock-in mice fed diets differing in protein and fat contents for 3 weeks. (a) Hepatic glycogen content, (b) mRNA expression of the gluconeogenic markers glucose-6-phosphatase (G6pc) and phosphoenolpyruvate carboxykinase 1 (Pck1), and (c) Western blot of the gluconeogenic markers Pck1. Values are means, with their standard errors represented by vertical bars. Values are expressed relative to the male low-fat (LF)/low-protein (LP) mouse group (=1; original data are given in online supplementary Table S5). The calculated effects of the threeway ANOVA (high protein $(\mathrm{HP})$, high fat $(\mathrm{HF})$ and sex) and interactions $(\mathrm{HP} \times \mathrm{HF}, \mathrm{HP} \times$ sex, $\mathrm{HF} \times$ sex and $\mathrm{HF} \times \mathrm{HP} \times$ sex) are given in online supplementary Table S6(F). $\square$, LF/LP; $\square$, LF/HP; $\square, H F / L P ; \square, H F / H P$.

and protein content (Fig. 4(c)). The expression of glucose6-phosphatase $(G 6 p c)$ was higher in male mice $(P=0.025)$, in particular, when fed a HF diet $(\mathrm{HF} \times \operatorname{sex}: P=0.006)$.

\section{A high dietary protein content reduces the expression of inflammatory markers}

Relative to those of control C57BL/6J mice, the livers of APOE2ki mice exhibit a pro-inflammatory phenotype, especially those of female mice ${ }^{(10,11)}$. In agreement with this, all haematoxylin and eosin-stained liver sections were found to exhibit clusters of inflammatory cells (Fig. 5(a); circles; online supplementary Fig. S2(A), top row). The CD68-positive Kupffer cells ${ }^{(22)}$ were homogeneously distributed across the liver sections and were more abundant in those of mice fed the HF diets (Fig. 5(b), upper row). The typically swollen, foam cell-like appearance of Kupffer cells of hyperlipidaemic mice $^{(10)}$ was also found in the liver sections of all mice, irrespective of the diet fed (Fig. 5(b), bottom row). Infiltrating/ activated macrophages, as identified by the expression of ITGAM (CD11b), were present as single or clustered positive cells (Fig. 5(c), online supplementary Fig. S2(A), bottom row). The inflammatory cell clusters in haematoxylin and eosin-stained liver sections co-localised with MPO-positive cell clusters in consecutive sections (Fig. 5(a) and (d); circles; online supplementary Fig. S2(B)). Although MPO is reportedly not expressed in murine macrophages ${ }^{(23)}$, it appears to be expressed in hepatic macrophages of NAFLD patients ${ }^{(24)}$. We, therefore, incubated a third serial section (Fig. 5(e)) to detect for the presence of LY6G, another neutrophil marker ${ }^{(25)}$. LY6G-positive cells co-localised with the clusters of MPO-positive cells, but were less abundant than MPOpositive cells (online supplementary Figs. S3(B) and S2). Because ITGAM could be detected in only frozen liver sections, we could not directly prove the co-localisation of
MPO- and LY6G-positive cell clusters with ITGAM-positive cells. However, as shown in Fig. 5, the ITGAM scores were strongly correlated with the corresponding MPO and LY6G scores in individual mice (Table 4; $P=0.005$ and OR 11.9 and $P=0.015$ and OR approximately 14 , respectively). Collectively, the data, therefore, show that the livers of APOE2ki mice with a marked infiltration of activated macrophages also accumulate neutrophils. No differences were found in the distribution of histopathological ITGAM scores $(P>0 \cdot 232$; Fig. 6(a); online supplementary Fig. S2(A), bottom row) or MPO/LY6G scores (online supplementary Fig. S3; $P>0$.917) between the dietary groups. In Fig. 5(c)-(e), pictures representing the scores $0-3$ are shown; serial sections from the respective dietary groups are shown in Fig. 5(a), (d) and (e). Representative examples of inflammatory cell clusters in haematoxylin and eosin-stained liver sections (top row) and examples with a score of 3 for ITGAM-positive cell infiltration (bottom row) for all the four dietary groups are shown in online supplementary Fig. S2(A).

The expression of a number of inflammatory marker genes was measured to evaluate the inflammatory responses in the liver to the diets more quantitatively. As expected, these markers (the protein content of the p65 subunit of NF- $\mathrm{kB}$ and its degree of phosphorylation (Fig. 6(b)) and the mRNA of Itgam, Cd68, chemokine (C-C motif) ligand $2(\mathrm{Ccl} 2) /$ monocyte chemotactic protein-1 (Mcp1), Toll-like receptor 4 (Tlr4) and Tnfo (Fig. 6(c) and (d))) were, with the exception of Tnfo, more highly expressed in female mice than in male mice (online supplementary Table S6(G); all $P \leq 0 \cdot 002$ ). A high dietary protein content decreased the hepatic concentrations of NF-кB

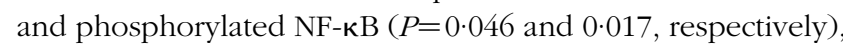
without affecting their ratio (activation state) significantly. The activation state of NF- $\mathrm{KB}$ was slightly higher (approximately $14 \%)$ in male APOE2ki mice than in female mice $(P=0.023)$, whereas the expression of Itgam and Mcp1 was lower 

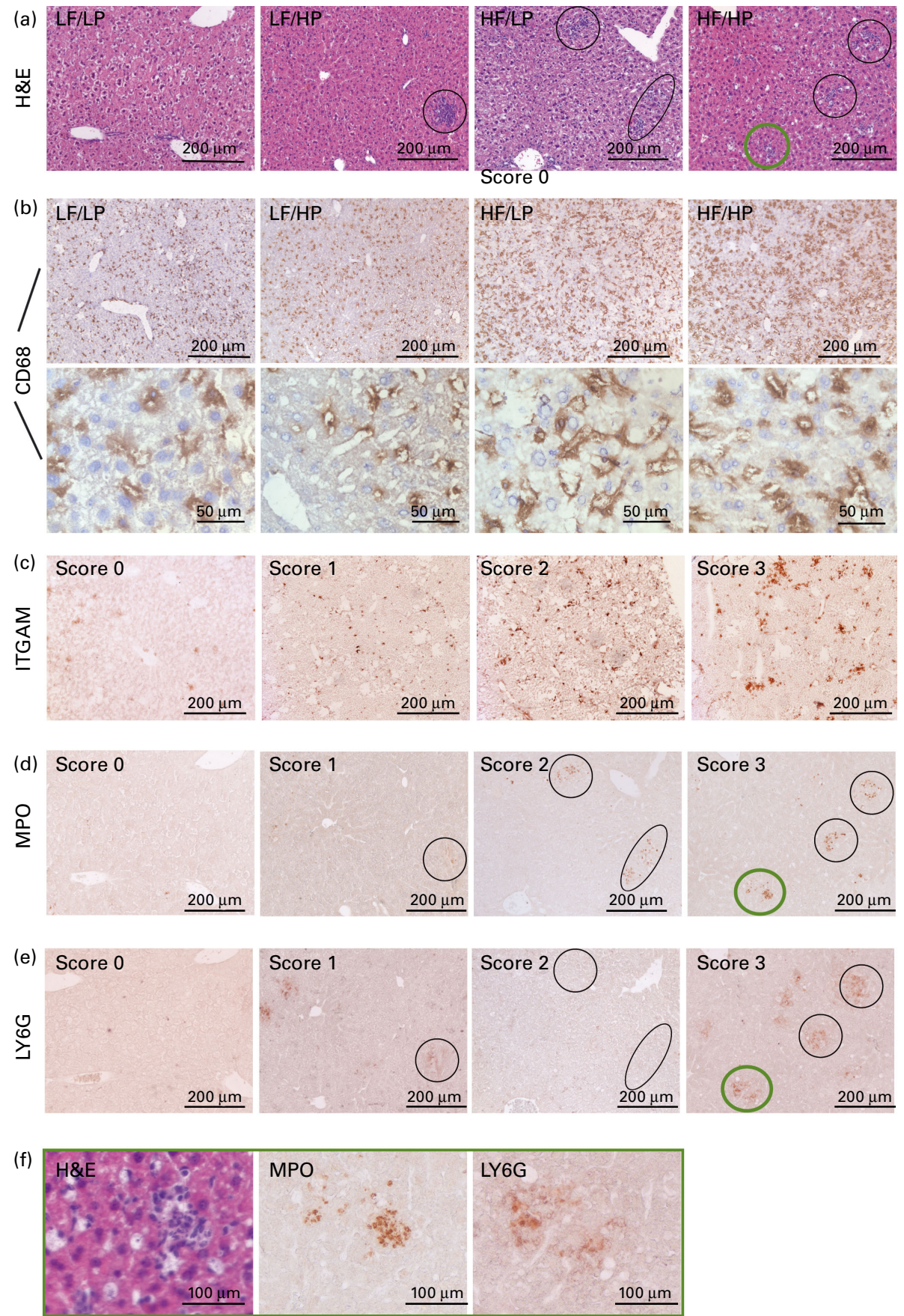

Fig. 5. Distribution of inflammatory cells in the livers of APOE2 knock-in mice fed diets differing in protein and fat contents for 3 weeks. Infiltration of inflammatory cells was heterogeneous. Examples of clusters of inflammatory cells are shown in this figure, while their quantification is shown in Fig. 6(a). Serial paraffinembedded sections were stained (except for cluster of differentiation 68 (CD68) and integrin $\alpha M$ (ITGAM), which required frozen sections) to compare with the (a) haematoxylin and eosin (H\&E) staining patterns. (b) Distribution of CD68-positive cells, with overview in the top row and magnification showing 'foamy' macrophages in the bottom row. (c) Distribution of ITGAM-positive ('activated') macrophages. Neutrophils were identified by the determination of (d) myeloperoxidase (MPO) and (e) lymphocyte antigen 6G (LY6G) expression, respectively. Circles indicate inflammatory foci, which are also visible in the H\&E-stained section. (f) Magnification of a cluster ( = green circle in the high fat (HF)/high protein (HP) subpanel of (a), (d) and (e)) stained with H\&E, MPO or LY6G, respectively. Note that for (c), (d) and (e), example pictures were selected in such a way to show all the different scoring levels. However, as shown in Fig. 6(a) for ITGAM, online supplementary Fig. S2(A) for ITGAM and online supplementary Fig. S3 for MPO and LY6G, there were no significant differences between the dietary groups with respect to these histopathological scores. LF, Low fat; LP, low protein. (A colour version of this figure can be found online at http://www.journals.cambridge.org/bjn)

$(P=0 \cdot 004$ and $0 \cdot 015$, respectively). No significant effect of the HP diets was observed on Tnf $\alpha$ or Tlr4 expression, but there was a slight increase in expression in male mice $(P=0 \cdot 040)$. A high dietary fat content did not affect the expression of these markers, albeit that of Itgam was more affected in female mice than in male mice $(P=0 \cdot 016)$.

Fibroblast growth factor 21 (FGF21) is a hormone that is significantly up-regulated in the liver with endoplasmic 
Table 4. Correlation between integrin $\alpha \mathrm{M}$ (ITGAM) and myeloperoxidase (MPO)/lymphocyte antigen 6G (LY6G) scores in the livers of APOE2 knock-in mice fed diets differing in protein and fat contents for 3 weeks ${ }^{*}$

\begin{tabular}{lrrr}
\hline & \multicolumn{3}{c}{ ITGAM score } \\
\cline { 2 - 4 } & 0 or 1 & 3 & Total \\
\hline MPO score & & & \\
0 or 1 & 12 & 3 & 15 \\
2 or 3 & 9 & 20 & 29 \\
Total & 21 & 23 & 44 \\
LY6G score & 1 & 9 & 10 \\
0 or 1 & 20 & 12 & 32 \\
2 or 3 & 21 & 21 & 42 \\
Total & &
\end{tabular}

* The frequency distribution of livers with low or high ITGAM and MPO or LY6G scores is given. ITGAM (CD11b)-positive cells represent activated macrophages, whereas MPO- and LY6G-positive cells represent neutrophils. A score of 0 or 1 is considered as low and a score of 2 or 3 as high. The data show that a high ITGAM score predicts a high MPO or LY6G score (Pearson $\chi_{(\mathrm{df}=1)}^{2}=9.5$, $P=0.005$; OR 11.9; risk ratio $=4.9$ and Pearson $\chi_{(\mathrm{df}=1)}^{2}=8$, $P=0.015$; OR 14 ; risk ratio $=7.5$, respectively).

reticulum stress ${ }^{(26)}$. Hepatic Fgf21 expression (Fig. 6(e)) and plasma FGF21 concentrations (Table 3) were reduced in APOE2ki mice fed the HP diets (online supplementary Table S6(E); $P=0.013$ and 0.002 , respectively). Other endoplasmic reticulum stress markers, such as CCAAT/enhancerbinding protein homologous protein (Chop), asparagine synthetase (glutamine-hydrolysing; Asns) and protein phosphatase 1 regulatory subunit 15A/growth arrest and DNA damage-inducible protein (Ppp1r15a/Gadd34) mRNA, did not respond to the dietary protein or fat content (Fig. 6(e)).

\section{Discussion}

The present study in APOE2ki mice and two other simultaneously performed studies in wild-type male (15) and female mice ${ }^{(27)}$ C57BL/6J mice showed that a high dietary protein content prevents and can even reverse the steatosis induced by a high dietary fat content. Increasing protein intake from that present in a LP diet to that in a HP diet (24E\% protein extra) also mitigates hepatic inflammation and cell stress in APOE2ki mice quantitatively and decreases plasma TC concentrations to a similar extent as leaving out the $0.2 \%$ cholesterol that is present in the LP diet ${ }^{(11)}$. However, a high dietary protein content does also induce an increase in plasma TAG concentrations. It should be kept in mind that the APOE2ki mouse on a HF diet is a monogenetic hyperlipidaemic model. Despite the fact that APOE2ki mice accumulate less fat when fed a HF diet compared with $\mathrm{C} 57 \mathrm{BL} / 6 \mathrm{~J}$ mice, the rapid inflammatory and steatotic responses of the liver make them a suitable model to study the effects of a $\mathrm{HP} / \mathrm{HF}$ diet on hepatic inflammation. In addition, the chosen intervention period is short. Both pro-inflammatory and steatotic effects of HF diets usually become more pronounced with longer duration of the intervention ${ }^{(28)}$.

We analysed both male and female APOE2ki mice, because lipid metabolism is an established sexually dimorphic feature ${ }^{(29,30)}$. Higher circulating oestrogen concentrations and oestrogen signalling and the continuous rather than episodic secretion patterns of growth hormone are usually held responsible for these features of the typical female phenotype ${ }^{(29,30)}$. Sex differences in lipogenesis, cholesterol synthesis and inflammation were more pronounced in APOE2ki mice than in wild-type mice (online supplementary Table S7). Accordingly, oestrogens are known to modulate apoE and its receptor, the LDL receptor-related protein (reviewed in Struble et al. $\left.{ }^{(31)}\right)$. However, female and male APOE2ki mice responded equally strongly to the lipid-lowering effect of a high dietary protein content, which demonstrates that this effect is not modulated by sex (online supplementary Table S8).

The anti-steatotic effect of a high-protein diet is not
caused by a decrease in dietary carbohydrate content

Changing the amount of one macronutrient in a diet necessarily affects the contribution of at least one of the other two macronutrients. In the present study, the carbohydrate content of the diets was adjusted to accommodate the changes in protein and/or fat contents, resulting in four diets with carbohydrate content ranging from 24 to $81 \mathrm{E} \%$ carbohydrate. This raised the question whether the observed effects on hepatic and plasma lipid concentrations were due to changes in dietary carbohydrate content rather than due to those in dietary protein content, as a $\mathrm{HF} / \mathrm{HP}$ diet is automatically a low-carbohydrate diet. Although plasma TAG concentrations were strongly correlated with dietary carbohydrate content in male $\left(R^{2} 0.9 ; P=0.004\right)$ and female $\left(R^{2} 0.7 ; P=0.03\right)$ APOE2ki mice, no such correlation was found for hepatic TAG concentrations. However, if data on the effects of three additional diets on hepatic TAG concentrations from two of our as-yet unpublished studies (with the same source of the macronutrients) were included, we could show that the contribution of dietary carbohydrate content $(0,24,33,48,57$, 66 and $81 \mathrm{E} \%)$ to hepatic TAG deposition depends on the dietary protein content (online supplementary Fig. S4; $R^{2} 0 \cdot 90$ for female mice and 0.60 for male mice) rather than on the dietary carbohydrate content $\left(R^{2} 0.36\right.$ for female mice and 0.06 for male mice).

The effects of dietary protein and fat contents on the liver are similar in APOE2 knock-in and wild-type mice

The most obvious differences between APOE2ki and wildtype mice are the 3- to 11-fold higher plasma concentrations of TAG and TC, the 20-40\% lower hepatic concentrations of TAG, NEFA, and TC, and the 20-30\% lower concentrations of glycogen in APOE2ki mice (online supplementary Table S7). Female APOE2ki mice greatly differed from wildtype female mice compared with their male counterparts by a higher expression of lipogenic genes (Pparg, Acaca, Fasn, stearoyl-CoA desaturase $1(S c d 1)$ and Srebf1), cholesterolsynthesising genes (Srebf2 and Hmgcr), cell-stress genes (Fgf21 and Chop) and inflammatory genes (Itgam, Cd68, Mcp1 and Tlr4) and an increased phosphorylation of NF- $\mathrm{B}$ (online supplementary Table S7). Furthermore, female 

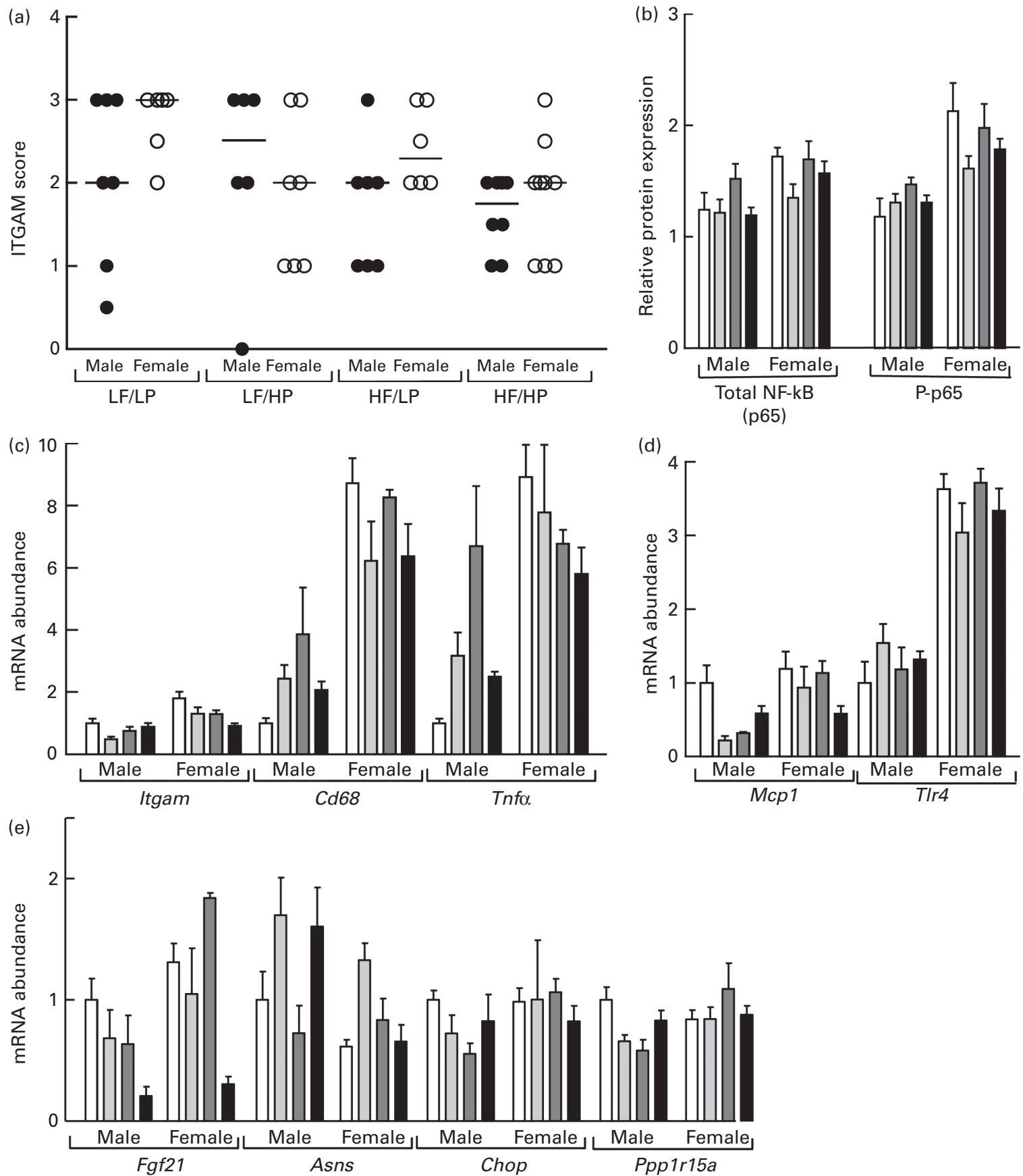

Fig. 6. Markers of hepatic inflammation in APOE2 knock-in mice fed diets differing in protein and fat contents for 3 weeks. (a) Frequency distribution of integrin $\alpha M$ (ITGAM)-positive cells and cell clusters (scores $0-3$ ). Horizontal lines indicate the medians. O, Female; $\bullet$, male. (b) Quantification of total NF- $\mathrm{kB}$ (p65) and phosphorylated p65 (P-p65). (c, d) Hepatic expression of inflammatory markers. (e) Hepatic expression of cell-stress markers. Values are means, with their standard errors represented by vertical bars. Values are expressed relative to the male low-fat (LF)/low-protein (LP) mouse group $(=1$; original data are given in online supplementary Table S5). The calculated effects of the three-way ANOVA (high protein (HP), high fat (HF) and sex) and interactions (HP $\times$ HF, HP $\times$ sex, $\mathrm{HF} \times$ sex and HF $\times \mathrm{HP} \times$ sex) are given in online supplementary Table S6(G). Cd68, cluster of differentiation 68; Mcp1, monocyte chemotactic protein-1; TIr4, Toll-like receptor 4; Fgf21, fibroblast growth factor 21; Asns, asparagine synthetase (glutamine-hydrolysing); Chop, CCAAT/enhancer-binding protein homologous protein; Ppp1r15a, protein phosphatase 1 regulatory subunit 15A. $\square, \mathrm{LF} / \mathrm{LP} ; \square, \mathrm{LF} / \mathrm{HP} ; \square, \mathrm{HF} / \mathrm{LP} ; \mathbf{\square}, \mathrm{HF} / \mathrm{HP}$.

APOE2ki mice exhibited a relatively low expression of the key cholesterol-catabolising gene Cyp7a1 and the key urea cycle gene argininosuccinate synthetase (Ass). The correlation of the comparatively high expression of urea cycle enzymes with relatively low levels of many amino acids (Ser, His, Gly, Thr, Ile, Phe and Orn) in male APOE2ki mice has been demonstrated earlier to point to a higher catabolism of amino acids ${ }^{(32,33)}$. These findings (online supplementary Table S7) indicate that the increased expression of enzymes involved in fatty acid and cholesterol synthesis and the high abundance of pro-inflammatory cells are the main features that distinguish the liver of APOE2ki mice from that of their 
wild-type counterparts. Despite these differences, the effect of a high dietary protein content on hepatic lipid content was as effective in APOE2ki mice as in wild-type mice, indicating that the effects of a HP diet are mediated by the same mechanism in both genotypes and that the APOE2dependent differences in fatty acid and cholesterol synthesis or inflammation are, in all likelihood, not involved in the steatosis-reducing effect of HP diets.

\section{High-protein diets have moderate effects on hepatic lipid metabolism}

The high concentrations of plasma (V)LDL in APOE2ki mice arise as a result of the lower clearance of these lipoproteins and their lipid $\operatorname{load}^{(16)}$. Despite a possibly compensatory increase in the expression of the fatty acid transporter $C d 36$ in the liver of APOE2ki mice, the lower lipid content in the liver of these mice compared with that in the liver of wild-type mice implies that the restricted import of fat into the liver has a pronounced anti-steatotic effect and that the increased expression of lipogenic genes in APOE2ki mice relative to wild-type mice (online supplementary Table S7) serves to compensate for the low hepatic TAG influx. In line with the interpretation that the lower cellular uptake of fat enhances carbohydrate metabolism, glucose tolerance in Apoe-deficient mice was better than that in wild-type mice $^{(34)}$. As both the HP and HF diets had no effect on or decreased the expression of lipogenic genes, it appears unlikely that they exert their effects via an APOE2-dependent decrease in the import of lipids.

The HP diets exerted few moderate, but stimulatory, effects on the expression of enzymes involved in lipid oxidation. In addition, the HP diets induced a pronounced increase in hepatic PCK1 protein expression in both wild-type and APOE2ki mice $^{(15,27)}$, which points to a higher, amino acid-dependent production of malate in the mitochondria. The relatively low plasma glucose and hepatic glycogen concentrations in these mice further suggest that the products of amino acid catabolism are not converted into glucose or glycogen, but largely used for pyruvate cycling. The livers of mice on a HP diet share this metabolic condition with fatty livers, in which Pck1 expression and flux are also increased without much effect on glucose output or glycogen accumulation ${ }^{(2,3)}$. In aggregate, these findings suggest that mitochondrial metabolism plays a key role in the effects of a HP diet.

\section{A high dietary protein content may decrease chylomicron clearance}

Fig. 3 shows a clear increase in TAG concentrations and a decrease in the TC content of the plasma (V)LDL fraction of APOE2ki mice fed the HP diets. FPLC does not separate VLDL and chylomicron remnants and so the high plasma TAG concentrations may originate in part from these remnants (see the prominent APOB48 band in Fig. 3(d)), which are absent in the plasma of fasted mice. Our data do not indicate whether the HP diet-induced increase in plasma TAG concentrations is due to an increased secretion of VLDL from the liver or a decreased plasma lipoprotein-lipase activity. The finding that a high dietary protein content restored the approximately $15 \%$ reduction in VLDL-TAG secretion rate in mice fed a HF diet ${ }^{(35)}$ does not seem to suffice to explain the HP dietinduced 4-fold increase in plasma VLDL-TAG content and, therefore, argues against the first alternative. Furthermore, increases in dietary protein (and fat) content decreased plasma APOB and APOE concentrations in a concentrationdependent manner. Lower protein and higher TAG contents of the chylomicrons may reflect a lower lipoprotein-lipase activity. In agreement with this, a high dietary protein content has been found to slow chylomicron clearance in human subjects fed a HP diet (28 v. 16 E\% dietary protein) after a fat tolerance test ${ }^{(36)}$.

\section{A high dietary protein content mitigates the pro-inflammatory state of the liver in APOE2 knock-in mice}

The increased susceptibility of APOE2ki mice to hepatic inflammation is closely associated with their high plasma TC and TAG concentrations, because decreasing plasma cholesterol concentrations by feeding a cholesterol-free $\operatorname{diet}^{(10,11)}$ or reducing plasma TC concentrations with $\operatorname{PPAR} \alpha, \operatorname{PPAR} \gamma$ or liver X receptor agonists ${ }^{(37,38)}$ decreases hepatic TC concentrations and inflammation in APOE2ki mice. A HP diet was found to reduce plasma and hepatic TC concentrations to a similar extent as a cholesterol-free, but otherwise identical diet $^{(11)}$. However, the TC-lowering effect of a high dietary protein content was less pronounced in the presence of a high dietary fat content, indicating that the effect was offset by the simultaneous increase in plasma TAG concentrations. Recent evidence argues in favour of an important role of oxidised LDL in hepatic inflammation ${ }^{(13)}$. The increased expression of $C d 36$ may make the liver of female APOE2ki mice more susceptible to the increased plasma oxidised LDL concentrations $^{(39)}$.

The clusters of inflammatory cells that were visible in the haematoxylin and eosin-stained liver sections of APOE2ki mice co-localised with MPO- and LY6G-positive cell clusters, although not each and every cell within a cluster appeared to express all markers. The co-localisation of ITGAM and LY6G may help identify polymorphonuclear myeloid-derived suppressor cells rather than mature macrophages, which attenuate inflammation and preserve insulin sensitivity in the livers of obese mice ${ }^{(40)}$. The co-localisation of MPO- and ITGAM/ LY6G-positive cells, therefore, suggests that the activation of compensatory mechanisms mitigates the effect of Kupffer cell activation on the development of steatohepatitis. This finding may well explain why the inflammatory response in the liver of APOE2ki mice is maximal between 1 and 3 weeks on a HF diet and gradually declines thereafter ${ }^{(17)}$. Even though the HP diets did not change the liver histology of APOE2ki mice, biochemical analysis (NF- $\mathrm{kB}$ concentration and degree of phosphorylation and the expression of inflammatory markers Itgam and $M c p 1$ and that of the cell-stress marker Fgf21) showed that the inflammatory cells were less activated. 


\section{Conclusion}

A HP diet has a pronounced anti-steatotic effect on the liver, even in APOE2ki mice with livers in a pro-inflammatory state. After studying the effect of a HP diet in wild-type mice, we concluded that a HP diet reduces steatosis via multiple moderate, but synergistic positive effects on lipid metabolism, cell stress and inflammation ${ }^{(15)}$. In the present study carried out in a more extreme, hyperlipidaemic model, we could exclude a major contribution of lipogenesis, cholesterol synthesis and inflammation. The decrease in plasma leptin and hepatic fat concentrations and the increase in PCK1 protein expression without an increase in hepatic glycogen content or glucose output and in Ppargc1a and Acox expression point towards a HP diet-mediated increase in mitochondrial metabolism. Such a mechanism is underscored by the recent finding in human subjects that TCA cycling is increased in patients with NAFLD ${ }^{(33)}$.

\section{Supplementary material}

To view supplementary material for this article, please visit http://dx.doi.org/10.1017/S0007114514001986

\section{Acknowledgements}

The authors thank Patrick van Gorp (Department of Molecular Genetics) for providing the APOE2ki mice and helping with the FPLC analysis and Drs Frank G. Schaap and Theo B. M. Hakvoort (Academic Medical Center, Amsterdam) for assaying plasma FGF21 and amino acid concentrations, respectively. They also thank Paul van Dijk and Els Terwindt for providing technical support.

The present study was supported by grant A105 from the Nutrigenomics consortium and by the graduate school VLAG, Wageningen, The Netherlands.

The authors' contributions are as follows: S. C. G. C. and T. M. C. were responsible for acquiring, analysing, and interpreting the data and drafting the manuscript; C. H. C. D., W. H. L. and S. E. K. conceived and designed the study, supervised the analysis and interpretation of the data, reviewed and revised the manuscript, and approved the final version of the manuscript.

None of the authors has any conflicts of interest to declare.

\section{References}

1. Brunt EM (2010) Pathology of nonalcoholic fatty liver disease. Nat Rev Gastroenterol Hepatol 7, 195-203.

2. Iozzo P, Bucci M, Roivainen A, et al. (2010) Fatty acid metabolism in the liver, measured by positron emission tomography, is increased in obese individuals. Gastroenterology 139, $846-856$

3. Sunny NE, Parks EJ, Browning JD, et al. (2011) Excessive hepatic mitochondrial TCA cycle and gluconeogenesis in humans with nonalcoholic fatty liver disease. Cell Metab 14, 804-810.

4. Puri P, Baillie RA, Wiest MM, et al. (2007) A lipidomic analysis of nonalcoholic fatty liver disease. Hepatology $\mathbf{4 6}$ 1081-1090.
5. Erion DM \& Shulman GI (2010) Diacylglycerol-mediated insulin resistance. Nat Med 16, 400-402.

6. Satapati S, Sunny NE, Kucejova B, et al. (2012) Elevated TCA cycle function in the pathology of diet-induced hepatic insulin resistance and fatty liver. J Lipid Res 53, 1080-1092.

7. Wobser H, Dorn C, Weiss TS, et al. (2009) Lipid accumulation in hepatocytes induces fibrogenic activation of hepatic stellate cells. Cell Res 19, 996-1005.

8. de Meijer VE, Kalish BT, Puder M, et al. (2010) Systematic review and meta-analysis of steatosis as a risk factor in major hepatic resection. Br J Surg 97, 1331-1339.

9. Tous M, Ferre N, Camps J, et al. (2005) Feeding apolipoprotein E-knockout mice with cholesterol and fat enriched diets may be a model of non-alcoholic steatohepatitis. Mol Cell Biochem 268, 53-58.

10. Wouters K, van Gorp PJ, Bieghs V, et al. (2008) Dietary cholesterol, rather than liver steatosis, leads to hepatic inflammation in hyperlipidemic mouse models of nonalcoholic steatohepatitis. Hepatology 48, 474-486.

11. Comhair TM, Garcia Caraballo SC, Dejong CHC, et al. (2011) Dietary cholesterol, female gender and $n-3$ fatty acid deficiency are more important factors in the development of non-alcoholic fatty liver disease than the saturation index of the fat. Nutr Metab (Lond) 8, 4

12. Knouff C, Briand O, Lestavel S, et al. (2004) Defective VLDL metabolism and severe atherosclerosis in mice expressing human apolipoprotein $\mathrm{E}$ isoforms but lacking the LDL receptor. Biochim Biophys Acta 1684, 8-17.

13. Bieghs V, Wouters K, van Gorp PJ, et al. (2010) Role of scavenger receptor A and CD36 in diet-induced nonalcoholic steatohepatitis in hyperlipidemic mice. Gastroenterology 138, 2477-2486.

14. Freudenberg A, Petzke KJ \& Klaus S (2012) Comparison of high-protein diets and leucine supplementation in the prevention of metabolic syndrome and related disorders in mice. J Nutr Biochem 23, 1524-1530.

15. Garcia-Caraballo SC, Comhair TM, Verheyen F, et al. (2013) Prevention and reversal of hepatic steatosis with a highprotein diet in mice. Biochim Biophys Acta 1832, 685-695.

16. Sullivan PM, Mezdour H, Quarfordt SH, et al. (1998) Type III hyperlipoproteinemia and spontaneous atherosclerosis in mice resulting from gene replacement of mouse Apoe with human Apoe*2. J Clin Invest 102, 130-135.

17. Bieghs V, Van Gorp PJ, Wouters K, et al. (2012) LDL receptor knock-out mice are a physiological model particularly vulnerable to study the onset of inflammation in nonalcoholic fatty liver disease. PLOS ONE 7, e30668.

18. Reeves PG, Nielsen FH \& Fahey GC Jr (1993) AIN-93 purified diets for laboratory rodents: final report of the American Institute of Nutrition ad boc writing committee on the reformulation of the AIN-76A rodent diet. J Nutr 123, 1939-1951.

19. Horton JD, Shimano H, Hamilton RL, et al. (1999) Disruption of LDL receptor gene in transgenic SREBP-1a mice unmasks hyperlipidemia resulting from production of lipid-rich VLDL. J Clin Invest 103, 1067-1076.

20. Roehrig KL \& Allred JB (1974) Direct enzymatic procedure for the determination of liver glycogen. Anal Biochem 58, 414-421.

21. Parks EJ, Krauss RM, Christiansen MP, et al. (1999) Effects of a low-fat, high-carbohydrate diet on VLDL-triglyceride assembly, production, and clearance. J Clin Invest 104, 1087-1096.

22. Kinoshita M, Uchida T, Sato A, et al. (2010) Characterization of two F4/80-positive Kupffer cell subsets by their function and phenotype in mice. J Hepatol 53, 903-910. 
23. McMillen TS, Heinecke JW \& LeBoeuf RC (2005) Expression of human myeloperoxidase by macrophages promotes atherosclerosis in mice. Circulation 111, 2798-2804.

24. Brown KE, Brunt EM \& Heinecke JW (2001) Immunohistochemical detection of myeloperoxidase and its oxidation products in Kupffer cells of human liver. Am J Pathol 159, 2081-2088.

25. Daley JM, Thomay AA, Connolly MD, et al. (2008) Use of Ly6G-specific monoclonal antibody to deplete neutrophils in mice. J Leukoc Biol 83, 64-70.

26. Schaap FG, Kremer AE, Lamers WH, et al. (2013) Fibroblast growth factor 21 is induced by endoplasmic reticulum stress. Biochimie 95, 692-699.

27. Garcia Caraballo SC, Comhair TM, Houten SM, et al. (2014) High-protein diets prevent steatosis and induce hepatic accumulation of monomethyl branched-chain fatty acids in female mice. Nutr Biochem (In the Press).

28. Gaemers IC, Stallen JM, Kunne C, et al. (2011) Lipotoxicity and steatohepatitis in an overfed mouse model for nonalcoholic fatty liver disease. Biochim Biophys Acta 1812, $447-458$.

29. Cortright RN \& Koves TR (2000) Sex differences in substrate metabolism and energy homeostasis. Can J Appl Physiol 25, $288-311$.

30. Waxman DJ \& O'Connor C (2006) Growth hormone regulation of sex-dependent liver gene expression. Mol Endocrinol 20, 2613-2629.

31. Struble RG, Cady C, Nathan BP, et al. (2008) Apolipoprotein E may be a critical factor in hormone therapy neuroprotection. Front Biosci 13, 5387-5405.
32. Johnson DJ \& Anderson GH (1982) Prediction of plasma amino acid concentration from diet amino acid content. Am J Physiol 243, R99-R103.

33. Moundras C, Remesy C \& Demigne C (1993) Dietary protein paradox: decrease of amino acid availability induced by high-protein diets. Am J Physiol 264, G1057-G1065.

34. Hofmann SM, Perez-Tilve D, Greer TM, et al. (2008) Defective lipid delivery modulates glucose tolerance and metabolic response to diet in apolipoprotein E-deficient mice. Diabetes 57, 5-12.

35. Schwarz J, Tome D, Baars A, et al. (2012) Dietary protein affects gene expression and prevents lipid accumulation in the liver in mice. PLOS ONE 7, e47303.

36. Bortolotti M, Schneiter P \& Tappy L (2010) Effects of dietary protein on post-prandial lipid metabolism in healthy humans. e-SPEN 5, e191-e197.

37. Shiri-Sverdlov R, Wouters K, van Gorp PJ, et al. (2006) Early diet-induced non-alcoholic steatohepatitis in APOE2 knockin mice and its prevention by fibrates. J Hepatol 44, 732-741.

38. Collino M, Aragno M, Castiglia S, et al. (2010) Pioglitazone improves lipid and insulin levels in overweight rats on a high cholesterol and fructose diet by decreasing hepatic inflammation. Br J Pharmacol 160, 1892-1902.

39. Stewart CR, Stuart LM, Wilkinson K, et al. (2010) CD36 ligands promote sterile inflammation through assembly of a Toll-like receptor 4 and 6 heterodimer. Nat Immunol $\mathbf{1 1}$ 155-161.

40. Xia S, Sha H, Yang L, et al. (2011) Gr $-1^{+} \mathrm{CD}_{11 b^{+}}$myeloidderived suppressor cells suppress inflammation and promote insulin sensitivity in obesity. J Biol Chem 286, 23591-23599. 